\title{
ВИЗИТ ПАПЫ ФРАНЦИСКА В АБУ-ДАБИ В КОНТЕКСТЕ МЕЖРЕЛИГИОЗНОГО ДИАЛОГА И МИГРАЦИОННОГО КРИЗИСА
}

\begin{abstract}
Аннотация. В статье предпринята попытка анализа исторического визита папь Франииска в Абу-Даби 3-5 февраля 2019 г. Авторитетные исламские лидеры Совета мусульманских старейшин и иерархи католической церкви признали, что этот визит внёс серьёзную лепту в упрочение мира и стабильности на Ближнем Востоке. Декларация "О человеческом братстве во имя мира и мирного сосуществования», подписанная папой Франциском и верховным имамом Мечети Аль-Азхар, заложила основы плодотворного взаимодействия мусульман и христиан в регионе и может побудить другие государства исламского мира отказаться от исламского фундаментализма, встать на путь умеренности. Католическая община ОАЭ восприняла приезд понтифика как жест солидарности, стремление рассказать всему миру о том, что значит исповедовать Христа в нехристианском обществе. В своей проповеди папа Франциск привлёк внимание христианской Европь к нуждам мигрантов-христиан в исламском мире и признал анахроничной политику запретов и ограничений, побудив европейцев рассматривать миграциионные прочессы в позитивном ключе.

Ключевые слова: папа Франциск, католическая ичерковь, ислам, Ватикан, Объединённые Арабские Эмираты, Абу-Даби, межрелигиозный диалог, миграционный кризис, католическая община ОАЭ, преследование христиан, умеренный ислам.
\end{abstract}

Визит папы Франциска в Абу-Даби 3-5 февраля 2019 г. по праву считается историческим. Объединённые Арабские Эмираты - не первое государство в мусульманском мире, которое посетил понтифик: он был, в частности, в Египте, Турции, Иордании и других странах. Особенность этой поездки в том, что она была заявлена как пастырский визит папы римского на Аравийский полуостров. Путешествие в Абу-Даби - 27-й по счёту апостольский визит главы католической церкви, ОАЭ - 41-е государство ${ }^{1}$, которое он посетил с момента избрания в 2013 г.

Прецедентом послужила другая историческая встреча - встреча папы Павла VI (Дж. Монтини, понтификат 1963-1978) с шахом Мохаммедом Реза Пехлеви в Тегеране в 1970 г., цель которой также была заявлена как «цель... духовного порядка» ${ }^{2}$. Очевидно, что намеченное было достигнуто, поскольку после исламской революции 1979 г. Святой Престол сохранил в Тегеране дипломатическое представительство и в 1979-1981 гг. оказывал пастырскую

\footnotetext{
(C) Язькова Вероника Евгеньевна - кандидат исторических наук, старший научный сотрудник Центра по изучению проблем религии и обшества Отдела социальных и политических исследований ИЕ РАН. Aдpec: 125009, Россия, Москва, ул. Моховая, д. 11, стр. 3. E-mail: yazkova@yandex.ru.

DOI: http://dx.doi.org/10.15211/vestnikieran12019156164

${ }^{1}$ Putzolu J.C. Papa negli Emirati. Ministro Al Jaber: viaggio nel segno del dialogo interreligioso. Città del Vaticano, 01.02.2019. URL: www.vaticannews.va/it/papa/news/2019-02/francesco-negli-emirati-arabi-uniti-dialogo-interreligio so.html.

${ }_{2}^{2}$ Discorso del Santo Padre Paolo VI. Aeroporto di Teheran, Iran, 26.11.1970. URL: http://w2.vatican.va/content/paulvi/it/speeches/1970/documents/hf_p-vi_spe_19701126_aeroporto-teheran.html.
} 
поддержку заложникам-католикам ${ }^{1}$. Однако именно папа Монтини положил начало встречам в русле межрелигиозного диалога: «Мы надеемся, - заявлял он, - что наш приезд принесёт плоды более тесного взаимодействия общин различных национальностей и религиозных конфессий в этой части света» ${ }^{2}$. Посетив Святую Землю, государства исламского мира, Индию, Азию, Африку, Океанию, Австралию, Латинскую Америку, Павел VI стал первым «папойпаломником», открыв тем самым путь своему знаменитому преемнику - Иоанну Павлу II.

Поездка нынешнего папы в ОАЭ в начале февраля 2019 г. преследовала те же цели. Подготовившими её событиями можно считать следующие: установление дипломатических отношений между Святым престолом и ОАЭ в 2007 г., визит в Ватикан наследного принца ОАЭ шейха Мухаммеда бин Зайда аль Нахайяна в сентябре 2016, в ходе которого шейх заявил о намерении «сотрудничать в деле восстановления мира и стабильности во всём мире» ${ }^{3}$, выступление папы Франциска с речью о межрелигиозном диалоге в египетском университете Аль-Азхар, крупнейшем центре суннитского ислама, в апреле 2017 г., последовавшее за тем в 2018 г. приглашение посетить Абу-Даби. Важно отметить, что приезд понтифика был запланирован на 2019 г., объявленный властями ОАЭ «годом толерантности» ${ }^{4}$

Визит главы католической церкви в Абу-Даби не испытывает недостатка в символике. Её выбор - и это типично для папы Франциска - как всегда не случаен, он вскрывает глубинные подтексты, актуализирует библейские аллюзии, задействует общие исторические, религиозные, культурные коды человечества. Голубь с оливкой ветвью в клюве, ставший эмблемой апостольской поездки, отсылает к рассказу о Великом потопе и Ноевом Ковчеге, который присутствует во многих религиозных традициях и который сегодня, превратившись в «ковчег братства», поможет «бороздить моря посреди бурь нашего мира» ${ }^{5}$. Строка из знаменитой молитвы святого Франциска Ассизского ${ }^{6}$ «Сделай меня орудием Твоего мира», избранная девизом визита, подчёркивает особую связь Бергольо со святым, чьё имя он взял после восшествия на папский престол, стремление сделаться миротворцем, «братом, ищущим мира с братьями» по примеру Франциска Ассизского, который так же без оружия, с одним Евангелием в руках встретился с султаном Египта Аль-Камилем Насиром ад-Дином Мухаммадом ибн Ахмадом $^{7}$ (800-летнюю годовщину легендарной встречи отметили 1-3 марта 2019 г.) $)^{8}$. Связь

\footnotetext{
${ }^{1}$ Стремидловский С. Шииты и католики: Ватикан и Иран притягивает друг к другу, ИА Regnum, 25.01.2016. URL: https://regnum.ru/news/2063802.html.

${ }_{2}$ Discorso del Santo Padre Paolo VI. Aeroporto di Teheran, Iran, 26.11.1970. URL: http://w2.vatican.va/content/paulvi/it/speeches/1970/documents/hf_p-vi_spe_19701126_aeroporto-teheran.html.

3 Pérez S. Viaggio storico, L’Osservatore Romano, 02.02.2019. URL: http://www.osservatoreromano.va/it/news/viag gio-storico.

${ }^{4}$ Putzolu J.C. Papa negli Emirati. Ministro Al Jaber: viaggio nel segno del dialogo interreligioso. Città del Vaticano, 01.02. 2019. URL: www.vaticannews.va/it/papa/news/2019-02/francesco-negli-emirati-arabi-uniti-dialogo-interreligioso.html.

5 Цит. Франциска I по: Сакун О. Папа в Абу-Даби: сегодня Бог призывает нас войти вместе в ковчег братства, Vatican News, град Ватикан, 04.02.2019. URL: https://www.vaticannews.va/ru/pope/news/2019-02/ru-pope-francisuae-founders-memorial.html.

6 «Господи, сделай меня орудием Твоего мира, / Там, где ненависть, дай мне приносить любовь, / Там, где обида - приносить прощение, / Там, где раздоры - приносить примирение, / Там, где сомнения - приносить веру, / Там, где заблуждения - приносить истину, / Там, где отчаяние - приносить надежду, / Там, где тьма - приносить свет, / Там, где печаль - приносить радость. / Дай мне, Господи, не ждать утешения, а утешать, / Не ждать понимания, а понимать, / Не ждать любви, а любить! / Ибо, только кто даёт, тот обретает, / Только кто о себе забывает - тот находит себя, / Только кто прощает - тот будет прощён, / Только кто умирает - тот воскресает для жизни вечной!» (Молитва святого Франциска о мире. / Православный портал. / https://omolitvah.ru/molitvy/molitvy-svyatogofrantsiska/).

7 Джаннат С.М. Франциск Ассизский и Ислам. 25.04.2005. URL: http://islam.ru/content/analitics/30153; Аббясов P. Размышления очевидца события. Послесловие к визиту Папы римского Франциска в Объединённые Арабские Эмираты, 07.03.2019. URL: https://muslim.ru/articles/274/23175/

${ }^{8}$ Сакун О. Послание Папы по случаю 800-летия встречи св. Франциска с султаном Аль-Маликом, Vatican News, град Ватикан, 01.03.2019. URL: https://www.vaticannews.va/ru/world/news/2019-03/poslanie-papy-po-sluchayu-800letiya-vstrechi-sv-franciska.html.
}

Научно-аналитический вестник ИЕ РАН, 2019, №1 
истории и современности подкрепляется цитированием слов старца Зосимы из романа Ф.М. До-стоевского «Братья Карамазовы» о лжи, правде и уважении ${ }^{1}$.

Не менее «говорящим» можно считать состав папской свиты в лице госсекретаря, кардинала П. Паролина, префектов Конгрегации евангелизации народов и Конгрегации по делам восточных церквей, секретаря Папского совета по межрелигиозному диалогу. С принимающей стороны тон переговорам задало присутствие наследного принца ОАЭ и верховного имама Мечети Аль-Азхар шейха, доктора Ахмада Ат-Тайиба, имеющего непререкаемый авторитет в исламском мире.

Декларация «О человеческом братстве во имя мира и мирного сосуществования», подписанная папой Франциском и верховным имамом, преследует цель утверждать «культуру мира и взаимоуважения» там, где раньше насаждалась лишь «культура ненависти, несправедливости, насилия и кровопролития» ${ }^{2}$. Верховный имам заявил: «Религии не в ответе за войны, ны, которые под разными лозунгами ведутся во имя религий: за них отвечают те, кто проводят ошибочную политику, те, кто... задействуют некоторых религиозных деятелей в делах, не имеющих ничего общего с религией. Мы признаём, что некоторые религиозные лидеры дают ошибочную трактовку священным книгам» ${ }^{3}$. Надеждой для всей западной цивилизации, особенно для тех стран, через которые проходят и в которых оседают миграционные потоки, ста-ли слова верховного имама: «Я говорю мусульманам на Западе: встраивайтесь в общество... сохраняйте вашу религиозную идентичность и уважайте законы этих сообществ. Знайте, что их безопасность - это и ваша ответственность» ${ }^{4}$. Позиция д-ра Ахмада Ат-Тайиба Тайиба во время встречи с папой чрезвычайно важна. Это признают многие мусульмане, которые увидели в ней знак полной нормализации отношений между Аль-Азхаром и Святым Престолом, охладившихся после знаменитой Регенсбургской речи ${ }^{5}$ папы Бенедикта XVI в 2006 г. ${ }^{6}$ Хочется н-адеяться, что слова столь авторитетного лидера, как верховный имам, о необходимости противостоять сторонникам жёстких мер будут восприняты как руководство к действию и дадут пищу плодотворному диалогу.

В своей речи папа Франциск затронул широкий спектр общечеловеческих вопросов. Он говорил об опасности крайнего индивидуализма, утилитаризма, воинствующего материализма, навязываемых современной культурой «fake news», о справедливости, праве людей на религиозную свободу и свободу культа, о воспитании молодёжи в духе веротерпимости, мужестве «быть другим», о сакральности человеческой личности, недопустимости рабства и даже о защите достоинства ребёнка в цифровую эпоху. Подчеркнув исключительное значение встречи в Абу-Даби, понтифик назвал эту землю «цветущей пустыней» - страной, где песок соседствует с небоскрёбами, где встречаются Восток и Запад, культуры и религии. Папа Франциск предостерёг Эмираты от эскалации насилия в ближневосточном регионе, воздвижения новых демаркационных линий, монетизации отношений, упомянул Йемен, в котором ведутся боевые действия, Сирию, Ирак, Ливию ${ }^{7}$.

\footnotetext{
${ }^{1}$ Папа Римский Франциск процитировал Достоевского, находясь в землях Аравии, ИА Regnum, 04.02.2019. URL: https://regnum.ru/news/2565908.html.

${ }^{2}$ La religione non è mai violenza. L'intervento del Grande Imam di Al-Azhar, 05.02.2019. URL: http://www.osservato reromano.va/it/news/la-religione-non-e-mai-violenza.

${ }^{3}$ Ibid.

${ }_{5}^{4}$ Ibid.

5 Речь папы Бенедикта XVI в Регенсбургском университете (Бавария) была посвящена историческим и философским различиям ислама и христианства, союзу веры и разума. Протест исламского мира вызвало цитирование слов византийского императора XIV в. Мануила II Палеолога о пророке Мухаммаде.

${ }^{6}$ Аббясов Р. Размышления очевидца события. Послесловие к визиту Папы римского Франциска в Объединённые Арабские Эмираты, 07.03.2019. URL: https://muslim.ru/articles/274/23175/

7 Discorso del Santo Padre Francesco, Abu Dhabi, 04.02.2019. URL: http://w2.vatican.va/content/francesco/it/speeches
} Научно-аналитический вестник ИЕ РАН, 2019, №1 
В Абу-Даби Святейший Отец встретил поистине царские приём и почести ${ }^{1}$ не только в президентском дворце во время пышной аудиенции наследного принца Мухаммеда бин Зайда аль Нахайяна и эмира Дубая Мухаммеда бен Рашида, но и на протяжении всей поездки. Позже, отвечая на вопросы журналистов, он сосредоточился на позитивных моментах визита, заметив, что о христианофобии, преследовании христиан он и так говорит часто. Он заявил, что считает Эмираты современной открытой страной с прекрасной системой образования и воспитания подрастающего поколения, новаторскими научными разработками. Ислам этого государства папа назвал «открытым исламом диалога, братским и мирным» ${ }^{2}$. Особенно сильное впечатление произвела на него, по его признанию, встреча в Мечети шейха Зайда с Советом мусульманских старейшин, в работе которого приняли участие представители различных национальностей и культур, авторитетные богословы, в том числе «по крайней мере» один шиит $^{3}$. Что же касается Декларации «О человеческом братстве», то на вопрос журналистов, не вызовет ли её подписание толки среди консервативно настроенных католиков, папа Франциск ответил, что «с католической точки зрения документ ни на миллиметр не отступил от учения Второго Ватиканского Собора» ${ }^{4}$

Логическим завершением визита стала первая и самая массовая в истории Аравийского полуострова папская месса на крупнейшем стадионе страны Зайид Спортс Сити. На богослужении присутствовали 120 тыс. католиков и около 4 тыс. мусульман ${ }^{5}$. Объехав стадион на своём «папамобиле», Франциск I горячо поприветствовал собравшихся. Апостольский викарий Южной Аравии епископ Пауль Хиндер и община верных встретили папу в кафедральном соборе св. Иосифа (осн. в 1981 г.) - невысоком светлом здании, одной из двух католических церквей Абу-Даби. К слову сказать, разрешение на строительство первого католического храма в городе с выделением под него земли было дано прежними властями 22 июня 1963 г. Этот исторический декрет передал понтифику наследный принц Мухаммед бин Зайд аль Нахайян.

По разным данным, в стране насчитывается от 901тыс. до 1 млн католиков, что составляет примерно 10\% населения 6 . Это в основном трудовые мигранты из более 100 стран мира, прежде всего из Филиппин, Индии, Сирии, Пакистана, Ирака, Египта, Иордании, Кореи. Именно к ним была обращена речь понтифика. Известно, что, будучи выходцем из семьи итальянских иммигрантов в Аргентине, Хорхе Бергольо с особенным вниманием относится к нуждам мигрантов. В своей проповеди о евангельских заповедях блаженств папа назвал их «блаженными». Он подчеркнул, что именно многоязычие и многонациональность общины верных рождает «радостную полифонию веры». Заповеди Нагорной проповеди - это «стиль жизни», - уточнил он, - а не вызов для супермена, они дают отвагу преодолевать трудности и испытания в повседневной жизни ${ }^{7}$.

http://w2.vatican.va/content/francesco/it/speeches /2019/february/documents/papa-francesco_20190204_emiratiarabiincontrointerreligioso.html; Генуа Ж.M. Le Figaro (Франция): Папа Римский отстаивает свободу вероисповедания в OАЭ, 05.02.2019. URL: https://inosmi.ru/social/ 20190205/244518963.html.

${ }^{1}$ Папу Франциска встретили в Абу-Даби артиллерийским салютом и пролётом авиации. Сибирская католическая газета, 05.02.2019. URL: https://sib-catholic.ru/papu-frantsiska-vstretili-v-abu-dabi-artilleriyskim-salyutom-iproletom-aviatsii-foto-video/

2 Папа Франциск ответил на вопросы журналистов касательно его визита в ОАЭ. Сибирская католическая газета, 06.02.2019. URL: https://sib-catholic.ru/papa-frantsisk-otvetil-na-voprosyi-zhurnalistov-kasatelno-ego-vizita-v-oae/

3 Там же

4 Там же.

5 Papa Francesco celebra la Santa Messa ad Abu Dhabi: «Sono venuto per dirti: beato!», 05.02.2019. URL: https:// www.papafrancesco.net/papa-francesco-celebra-la-santa-messa-ad-abu-dhabi-venuto-dirti-beato/

${ }^{6}$ Matzuzzi M. La prima messa di Bergoglio nel Golfo e quella fede sempre viva dei cattolici emiratini. URL: https:// formiche.net/2019/02/papa-emirati-viaggio-cattolici/

${ }^{7}$ Papa Francesco celebra la Santa Messa ad Abu Dhabi: «Sono venuto per dirti: beato!», 05.02.2019. URL: https:// www.papafrancesco.net/papa-francesco-celebra-la-santa-messa-ad-abu-dhabi-venuto-dirti-beato/

Научно-аналитический вестник ИЕ РАН, 2019, №1 
Надо признать, что для 2,5 млн христиан Персидского залива, особенно для верующих соседних с Эмиратами государств, Саудовской Аравии, Катара или Йемена, где открыто исповедовать христианство запрещено, церквей нет, богослужения проводятся тайно, по домам, подобные слова папы - отнюдь не метафора, они наполнены вполне конкретным содержанием. Католики ОАЭ находятся в более выгодном положении, несмотря на то что де-факто христиане часто считаются гражданами второго сорта. Поскольку ислам - единственная государственная религия этой страны, невысокие католические храмы на её территории лишены наружных опознавательных знаков - крестов и колоколен, - так как единственными устремлёнными ввысь башнями должны оставаться минареты. И тем не менее, на территории государства действуют 9 католических храмов (они построены на землях, подаренных церкви властями или сданных в аренду за символическую плату ${ }^{1}$ ), открыты католические школы, рождественская месса собирает до 500 тыс. верующих, около 30 тыс. детей проходят занятия по катехизации, богослужения идут на основных европейских языках, на арабском, филиппинском, тамильском, урду, языке малаялам, конкани и др. ${ }^{2}$, местную общину окормляют 53 священника и 45 монахинь, действуют различные движения мирян, в том числе «Причастие и освобождение», «Опус Деи», «Фоколяры» ${ }^{3}$. Как заявил в интервью «Коррьере делла Сера» Апостольский викарий, 76-летний епископ, капуцин Пауль Хиндер, в Эмиратах христианам разрешено исповедовать свою веру, хотя и с оговорками: «Я реалист. Я живу здесь уже 15 лет и вижу, что ситуация меняется, есть прогресс... Я немного знаком с культурой мусульманских стран, и мы благодарны за такую свободу культа. О религиозной свободе говорить не приходится... но и эта относительная свобода - уже много» ${ }^{4}$. Всем этим католики обязаны благосклонности правящей династии. И хотя в Эмиратах, по сути, существуют два параллельных общества, встречаются случаи дискриминации христиан, особенно женщин, в целом же движение вперёд очевидно, «стакан наполовину полон, а не наполовину пуст» ${ }^{2},-$ заявил епископ Хиндер корреспонденту католического издания «Темпи».

В Европе оптимизм епископа Хиндера разделяется не всеми несмотря на то, что в целом визит папы получил высочайшую оценку в католической среде ${ }^{6}$. Говоря о ценности межрелили-гиозных встреч, католики-консерваторы с осторожностью относятся к политике «открытых объятий». По их мнению, диалог христианства с исламским миром затрудняют такие проявления исламского фундаментализма, как: запрет апостасии, или смены веры, которая в некоторых мусульманских государствах карается смертью; фундаментализм, казни, чуждый либе-ральной демократии тип государственного устройства, дискриминация христиан, нерав-

\footnotetext{
${ }^{1}$ Uguccioni C. Emirati Arabi, il vescovo Hinder: «Così cristiani e musulmani aspettano il Papa», La stampa, 31.01. 2019. URL: https://www.lastampa.it/2019/01/31/vaticaninsider/emirati-arabi-il-nunzio-aspettiamo-tutti-il-papa-ancheimusulmani-9H120rHoR5G4fmNk2wFhYK/pagina.html.

${ }^{2}$ Vechi G.G. Il Papa negli Emirati, Hinder, il vescovo realista. «Croci ancora vietate ma vediamo progressi»; Corriere della Sera, 03.02.2019. URL: https://www.corriere.it/esteri/19_febbraio_03/hinder-vescovo-realista-croci-ancora-vietate-ma-vediamo-progressi-38f6eb18-27f1-11e9-84f8-838f47b6747c.shtml?intcmp=googleamp.

${ }^{3}$ Casadei R. La sorprendente vitalità dei cattolici degli Emirati Arabi Uniti, dove vige la sharia, Tempi, 21.03.2018. URL: https://www.tempi.it/la-sorprendente-vitalita-dei-cattolici-degli-emirati-arabi-uniti-dove-vige-la-sharia/; Il Papa negli Emirati, dove vige la sharia ma la Chiesa è più vitale che in Europa, Tempi, 03.02.2019. URL: https://www.tempi.it/ papa-francesco-emirati-islam-sharia-chiesa/

${ }^{4}$ Vechi G.G. Il Papa negli Emirati, Hinder, il vescovo realista. «Croci ancora vietate ma vediamo progressi»; Corriere della Sera, 03.02.2019. URL: https://www.corriere.it/esteri/19_febbraio_03/hinder-vescovo-realista-croci-ancora-vietate-ma-vediamo-progressi-38f6eb18-27f1-11e9-84f8-838f47b6747c.shtml?intcmp=googleamp.

5 Il Papa negli Emirati, dove vige la sharia ma la Chiesa è più vitale che in Europa, Tempi, 03.02.2019. URL: https:// www.tempi.it/papa-francesco-emirati-islam-sharia-chiesa/

${ }^{6}$ Папа Франциск отслужил мессу в Абу-Даби, Голос Америки, 05.02.2019. URL: https://www.golos-ameriki.ru/a/ uae-pope/4773822.html; Светикова Е. Диалог христианства с исламом: зачем папа Римский Франциск прилетел в Абу-Даби, 04.02.2019. URL: https://rtvi.com/stories/dialog-khristianstva-s-islamom-zachem-papa-rimskiy-frantsiskpriletel-v-abu-dabi/
}

Научно-аналитический вестник ИЕ РАН, 2019, №1 
нопра-вие женщин, преобладание шариата над светскими законами, различие культурных ценностей. Как отмечает уч ный-иезуит А. Була, египтянин по происхождению, визит папы Франциска в Абу-Даби чрезвычайно важен. В силу своей открытости ОАЭ «могли бы... сыграть ключевую роль в выработке этих единых базовых ценностей и утверждения стабильного мира» ${ }^{1}$ в Заливе. Сам же «позитивный вектор и гуманистичный вектор развития» ${ }^{2}$ Эмиратов мо-жет послужить образцом для других государств исламского мира, побудить их отказаться от исламского экстремизма и фанатизма, преследования христиан, встать на путь умеренности. Последнее возможно только в условиях диалога и мирного сосуществования обеих религий.

Таким образом, воодушевление, с которым ближневосточные католики встретили в Абу-Даби своего папу, понятно и объяснимо. Небольшая по европейским меркам, но чрезвычайно активная, практикующая католическая община ОАЭ восприняла его приезд как жест солидарности с «церковью мигрантов», стремление рассказать всему миру о том, что значит исповедовать Христа в нехристианском обществе. «Местные католики не скрывают своей религиозной принадлежности, - подчеркнул епископ Хиндер. - Они уважают ислам, но не боязливы. Они смиренные, но отважные» ${ }^{3}$. Присутствие же 4 тыс. мусульман на мессе папы Бергольо, вышедшего к ним без оружия, как святой Франциск, какой бы ни была их истинная мотивация, бесспорно, свидетельствует о «потеплении» отношений между мусульманами и христианами в ОАЭ и создаёт исторический прецедент для других стран Залива.

Визит в Абу-Даби явился важным этапом не только межрелигиозного диалога, но и политики церкви в отношении миграционного кризиса. В своей проповеди папа Франциск привлёк внимание христианской Европы к нуждам мигрантов-христиан в исламском мире и признал анахроничной политику запретов и ограничений, побудив европейцев рассматривать миграционные процессы в позитивном ключе.

\section{Список литературы}

Аббясов Р. Размышления очевидца события. Послесловие к визиту Папы римского Франциска в Объединённые Арабские Эмираты, 07.03.2019. [Online]. URL: https://muslim.ru/ar ticles/274/23175/ (дата обращения 07.03.2019).

Генуа Ж.M. Le Figaro (Франция): Папа Римский отстаивает свободу вероисповедания в OАЭ, 05.02.2019. [Online]. URL: https://inosmi.ru/social/20190205/244518963.html (дата обращения 09.03.2019).

Джаннат C.M. Франциск Ассизский и Ислам, 25.04.2005. [Online]. URL: http://islam.ru/ content/analitics/30153 (дата обращения 05.02.2019).

Молитва святого Франциска о мире. Православный портал. [Online]. URL: https://omolit vah. ru/molitvy/molitvy-svyatogo-frantsiska/ (дата обращения 05.02.2019).

Папа Римский Франциск процитировал Достоевского, находясь в землях Аравии. ИА Regnum, 04.02.2019. [Online]. URL: https://regnum.ru/news/2565908.html (дата обращения 09.03. 2019).

Папа Франциск ответил на вопросы журналистов касательно его визита в ОАЭ. Сибир-

\footnotetext{
${ }^{1}$ Uno studioso gesuita esprime il suo giudizio sulla prossima visita papale negli Emirati Arabi Uniti, Chiesa e post concilio, 05.02.2019. URL: http://chiesaepostconcilio.blogspot.com/2019/02/uno-studioso-gesuita-esprime-il-suo.html.

2 Аббясов Р. Размышления очевидца события. Послесловие к визиту Папы римского Франциска в Объъединённые Арабские Эмираты, 07.03.2019. URL: https://muslim.ru/articles/274/23175/

${ }^{3}$ Uguccioni C. Emirati Arabi, il vescovo Hinder: «Così cristiani e musulmani aspettano il Papa», La stampa, 31.01. 2019. URL: https://www.lastampa.it/2019/01/31/vaticaninsider/emirati-arabi-il-nunzio-aspettiamo-tutti-il-papa-ancheimusulmani-9H120rHoR5G4fmNk2wFhYK/pagina.html.
}

Научно-аналитический вестник ИЕ РАН, 2019, №1 
ская католическая газета, 06.02.2019. [Online]. URL: https://sib-catholic.ru/papa-frantsisk-otve til-na-voprosyi-zhurnalistov-kasatelno-ego-vizita-v-oae/ (дата обращения 10.03.2019).

Папа Франциск отслужил мессу в Абу-Даби. Голос Америки, 05.02.2019. [Online]. URL: https://www.golos-ameriki.ru/a/uae-pope/4773822.html (дата обращения 10.03.2019).

Папу Франциска встретили в Абу-Даби артиллерийским салютом и пролётом авиации. Сибирская католическая газета, 05.02.2019. [Online]. URL: https://sib-catholic.ru/papu-frantsis ka-vstretili-v-abu-dabi-artilleriyskim-salyutom-i-proletom-aviatsii-foto-video/ (дата обращения 09.02.2019).

Сакун О. Папа в Абу-Даби: сегодня Бог призывает нас войти вместе в ковчег братства. Vatican News, град Ватикан, 04.02.2019. [Online]. URL: https://www.vaticannews.va/ru/pope/ news/2019-02/ru-pope-francis-uae-founders-memorial.html (дата обращения 08.03.2019).

Светикова Е. Диалог христианства с исламом: зачем папа Римский Франциск прилетел в Абу-Даби. 04.02.2019. [Online]. URL: https://rtvi.com/stories/dialog-khristianstva-s-islamomzachem-papa-rimskiy-frantsisk-priletel-v-abu-dabi/ (дата обращения 09.03.2019).

Стремидловский С. Шииты и католики: Ватикан и Иран притягивает друг к другу. ИА Regnum, 25.01.2016. [Online]. URL: https://regnum.ru/news/2063802.html (дата обращения 10.03.2019).

\section{References}

Abbyasov R. Rasmyshlienya ochevidza sobytya. Poslieslovye k visitu Papy rymskogo Frantsiska v Obiedinnyonnye Arabskye Emiraty. 07.03.2019. [Online]. URL: https://muslim.ru/articles/ 274/23175/ (дата обращения 07.03.2019).

Giannat S.M. Frantsisk Assisky y Islam. 25.04.2005. [Online]. URL: http://islam.ru/content/ analitics/30153 (дата обращения 05.02.2019).

Genua J.M. Le Figaro (France): Papa rymskiy otstaivayet svobodu veroispovedovanya v OAE. 05.02.2019. [Online]. URL: https://inosmi.ru/social/20190205/244518963.html (дата обращения 09.03.2019).

Molitva svyatogo Frantsiska o mire. Pravoslavny portal. [Online]. URL: https://omolitvah.ru/ molitvy/molitvy-svyatogo-frantsiska/ (дата обращения 5.02.2019).

Papa rymskiy Frantsisk protsetiroval Dostoievskogo, nahodyas' v zemliah Aravii. IA Regnum, 04.042019. [Online]. URL: https://regnum.ru/news/2565908.html (дата обращения 09.03.2019).

Papa Frantsisk otvetil na voprosy zhurnalistiv kasatel'no ego visita v OAE. Sibirskaya katolicheskaia gazeta, 6.02.2019. [Online]. URL: https://sib-catholic.ru/papa-frantsisk-otvetil-navoprosyi-zhurnalistov-kasatelno-ego-vizita-v-oae/ (дата обращения 10.03.2019).

Papa Frantsisk otsluzhil messu v Abu-Dhabi. Golos Ameriky, 05.02.2019. [Online]. URL: https://www.golos-ameriki.ru/a/uae-pope/4773822.html (дата обращения 10.03.2019).

Papu Frantsiska vstretili v Abu-Dhabi artilleriyskim salutom y prolyotom aviatsii. Sibirskaya katolicheskaia gazeta, 05.02.2019. [Online]. URL: https://sib-catholic.ru/papu-frantsiska-vstretili-vabu-dabi-artilleriyskim-salyutom-i-proletom-aviatsii-foto-video/ (дата обращения 09.02.2019).

Sakun O. Papa Папа v Abu-Dhabi: segodnya Bog prisyvaiet nas voyti vmeste v kovcheg bratstva. Vatican News, Vatican, 04.02.2019. [Online]. URL: https://www.vaticannews.va/ru/pope/ news/2019-02/ru-pope-francis-uae-founders-memorial.html (дата обращения 08.03.2019).

Svetikova E. Dialog khristianstva s islamom: zachem Papa rymskiy Frantsisk priletel v AbuDhabi. 04.02.2019. [Online]. URL: https://rtvi.com/stories/dialog-khristianstva-s-islamom-zachempapa-rimskiy-frantsisk-priletel-v-abu-dabi/ (дата обращения 09.03.2019).

Stremidlovskiy S. Shyity y katoliki: Vatikan y Iran prityagivayet drug k drugy. IA Regnum, 
25.01.2016.[Online]. URL: / https://regnum.ru/news/2063802.html (дата обращения 10.03.2019).

Casadei R. La sorprendente vitalità dei cattolici degli Emirati Arabi Uniti, dove vige la sharia. Tempi, 21.03.2018. [Online]. URL: https://www.tempi.it/la-sorprendente-vitalita-dei-cattolicidegli-emirati-arabi-uniti-dove-vige-la-sharia/ (дата обращения 05.02.2019).

Discorso del Santo Padre Francesco. Abu Dhabi, 04.02.2019. [Online]. URL: http://w2.vatican.

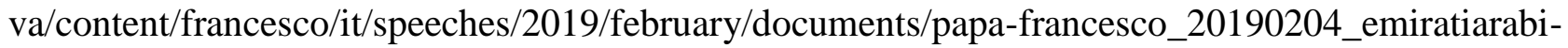
incontrointerreligioso.html (дата обращения 09.02.2019).

Discorso del Santo Padre Paolo VI. Aeroporto di Teheran, Iran, 26.11.1970. [Online]. URL: http://w2.vatican.va/content/paul-vi/it/speeches/1970/documents/hf_p-vi_spe_19701126_aeroportoteheran.html (дата обращения 09.02.2019).

Il Papa negli Emirati, dove vige la sharia ma la Chiesa è più vitale che in Europa. Tempi, 03.02. 2019. [Online]. URL: https://www.tempi.it/papa-francesco-emirati-islam-sharia-chiesa/ (дата обращения 08.03.2019).

La religione non è mai violenza. L’intervento del Grande Imam di Al-Azhar. 05.02.2019. [Online]. URL: http://www.osservatoreromano.va/it/news/la-religione-non-e-mai-violenza (дата обращения 08.03.2019).

Matzuzzi M. La prima messa di Bergoglio nel Golfo e quella fede sempre viva dei cattolici emiratini. [Online]. URL: https://formiche.net/2019/02/papa-emirati-viaggio-cattolici/(дата обращения 10.03.2019).

Papa Francesco celebra la Santa Messa ad Abu Dhabi: «Sono venuto per dirti: beato!», 05.02. 2019. [Online]. URL: https://www.papafrancesco.net/papa-francesco-celebra-la-santa-messa-adabu-dhabi-venuto-dirti-beato/ (дата обращения 08.03.2019).

Pérez S. Viaggio storico. L'Osservatore Romano, 02.02.2019. [Online]. URL: http://www. osservatoreromano.va/it/news/viaggio-storico (дата обращения 10.03.2019).

Putzolu J.C. Papa negli Emirati. Ministro Al Jaber: viaggio nel segno del dialogo interreligioso. Vatican News, Città del Vaticano, 01.02.2019. [Online]. URL: www.vaticannews.va/it/papa/news/ 2019-02/francesco-negli-emirati-arabi-uniti-dialogo-interreligioso.html (дата обращения 10.03. 2019).

Uguccioni C. Emirati Arabi, il vescovo Hinder: «Così cristiani e musulmani aspettano il Papa». La stampa, 31.01.2019. [Online]. URL: https://www.lastampa.it/2019/01/31/vaticaninsider/emiratiarabi-il-nunzio-aspettiamo-tutti-il-papa-anchei-musulmani-9H120rHoR5G4fmNk2wFhYK/pagina. html (дата обращения 08.03.2019).

Uno studioso gesuita esprime il suo giudizio sulla prossima visita papale negli Emirati Arabi Uniti. Chiesa e post concilio, 05.02.2019. [Online]. URL: http://chiesaepostconcilio.blogspot.com/ 2019/02/uno-studioso-gesuita-esprime-il-suo.html (дата обращения 09.03.2019).

Vechi G.G. Il Papa negli Emirati, Hinder, il vescovo realista. «Croci ancora vietate ma vediamo progressi». Corriere della Sera, 03.02.2019. [Online]. URL: https://www.corriere.it/esteri/19 febb raio_03/hinder-vescovo-realista-croci-ancora-vietate-ma-vediamo-progressi-38f6eb18-27f1-11e9-

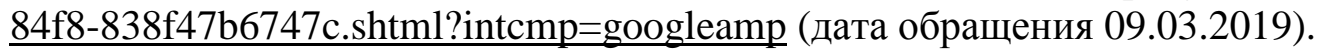




\title{
The Visit of Pope Francis in Abu dhabi in the context of Interreligious Dialogue and the Migration Crisis
}

Author. Veronica Yazkova, Candidate of Sciences (History), Master Researcher, Center of religion and society problems, Institute of Europe, Russian Academy of Sciences. Address: 11-3, Mokhovaya str., Moscow, Russia, 125009. E-mail: yazkova@yandex.ru.

\begin{abstract}
The article deals with the historical visit of Pope Francis to Abu Dhabi on February 3-5, 2019 Most of authoritative Islamic leaders of the Council of Muslim elders and hierarchs of the Catholic Church recognized the importance of this visit which contributed to consolidate peace and stability in the middle East. The Declaration on «Human brotherhood for peace and peaceful coexistence» signed by Pope Francis and the Supreme Imam of the al-Azhar Mosque laid foundation stones for fruitful interaction and cooperation between Muslims and Christians in the region. The Declaration can also encourage other States of the Islamic world to abandon Islamic fundamentalism and take the path of moderate Islam. The Catholic community of the UAE took the arrival of the Pontiff as manifestation of solidarity, desire to tell the world about what it means to confess Christ in a non-Christian society. In his sermon Pope Francis drew attention of the Christian Europe on the needs of Christian migrants in the Islamic world and recognized the anachronistic policies of prohibitions and restrictions, prompting Europeans to evaluate migration processes in a positive way.

Key words: Pope Francis, Catholic Church, Islam, Vatican, United Arab Emirates, Abu Dhabi, interreligious dialogue, migration crisis, Catholic community of the UAE. persecution of Christians, moderate Islam.
\end{abstract}

DOI: http://dx.doi.org/10.15211/vestnikieran12019156164 